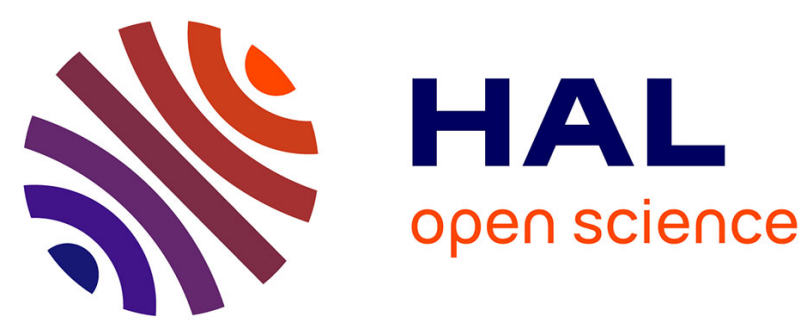

\title{
Hierarchical Multiporous Nickel for Oxygen Evolution Reaction in Alkaline Media
}

Sunpet Assavapanumat, Marisa Ketkaew, Patrick Garrigue, Véronique Lapeyre, Stéphane Reculusa, Chularat Wattanakit, Alexander Kuhn

\section{- To cite this version:}

Sunpet Assavapanumat, Marisa Ketkaew, Patrick Garrigue, Véronique Lapeyre, Stéphane Reculusa, et al.. Hierarchical Multiporous Nickel for Oxygen Evolution Reaction in Alkaline Media. ChemCatChem, 2019, 11 (24), pp.5951-5960. 10.1002/cctc.201901509 . hal-02509760

\section{HAL Id: hal-02509760 \\ https://hal.science/hal-02509760}

Submitted on 17 Mar 2020

HAL is a multi-disciplinary open access archive for the deposit and dissemination of scientific research documents, whether they are published or not. The documents may come from teaching and research institutions in France or abroad, or from public or private research centers.
L'archive ouverte pluridisciplinaire HAL, est destinée au dépôt et à la diffusion de documents scientifiques de niveau recherche, publiés ou non, émanant des établissements d'enseignement et de recherche français ou étrangers, des laboratoires publics ou privés. 
Hierarchical multiporous nickel for oxygen evolution reaction in alkaline media

Sunpet Assavapanumat,a,b Marisa Ketkaew,a,b Patrick Garrigue,a Véronique Lapeyre,a Stéphane Reculusa, a Chularat Wattanakit, $b$ * Alexander Kuhn, a *

Abstract: Electrochemical water splitting is a crucially important process for energy conversion and storage. In this context, we report the synthesis of hierarchical multiporous nickel nanosheets obtained by a templated two-step electrodeposition of nickel in the presence of silica beads and an assembly of nonionic surfactant in order to generate a combined macro- and mesoporous structure. Interestingly, the synergistic effect of these highly ordered meso- and macroporous structures promotes the catalytic performance for oxygen evolution reaction with one order of magnitude higher current densities, lower overpotentials and a better stability of the electrodes compared to flat nickel or electrodes having a single type of porosity. This example illustrates a promising strategy for the rational design of high-performance porous metals, not only in the frame of water electrolysis, but also for other electrocatalytic applications.

Introduction

The development of alternative sustainable energy conversion schemes to replace depleted fossil fuels is a key challenge for present scientific activities. For example, the splitting of water into oxygen and hydrogen is one of the most promising processes, because it can be used to produce efficiently clean and storable energy.1 The cathodic part of water splitting, hydrogen evolution reaction (HER), typically requires low overpotentials of around $100 \mathrm{mV}, 2$ whereas the anodic part, oxygen evolution reaction (OER), needs significantly higher overpotentials in the range of 300 to $500 \mathrm{mV}$ compared to commercial platinum-based catalysts due to sluggish electron transfer kinetics at many electrode surfaces. 3 In acidic solution, Ru- and Ir-based catalysts are well known as the most active electrocatalysts for OER because of their high performance at low overpotential.4 However, the limitations of high cost, scarcity and metal dissolution during the electrocatalytic process are somewhat slowing down practical industrial utilization. 5 Therefore, great efforts have been made to develop alternative catalysts based on non-precious metals, which are stable under basic conditions, such as nickel. foams, 6 nickel alloys, 7 nickel nitride, 8 nickel phosphides, 9 nickel selenide, 10 nickel oxide11 and nickel hydroxide.12 They have been studied as highly efficient and durable alternatives for OER in alkaline media.13

Despite these very promising reports on the development of nickel-based catalysts for OER, they may suffer from certain disadvantages, such as low active surface area and poor mass transport properties.14 To circumvent these problems, porous materials, composed of micropores, mesopores and macropores have been proposed over the past decade and exhibit synergistic effects of hierarchical porous structures.15 Typically, colloidal crystals (hard template) or surfactants (soft template), were used to control the final structure of porous metals and metal oxides.16 For example, hierarchical macro- and mesoporous platinum obtained by the electrodeposition of metal in the simultaneous presence of colloidal silica beads and sodium dodecyl sulfate (SDS) can improve significantly the efficiency of methanol oxidation due to an increase in internal surface area and improved mass transport.17

For the highly-controlled generation of macroporous structures, the Langmuir-Blodgett (LB) technique is a powerful tool,18 which is widely used for coating surfaces with mono- or multilayers of templates such as silica and polymer beads.19 The intrinsic advantages of the LB technique, in particular the precisely controllable layer-by-layer coating, allows designing materials for various 
applications ranging from analysis 20 and sensing 21 to separation membranes 22 and electrocatalysis. 23

Concerning mesoporous structures, there have been several reports about using assemblies of surfactants as templates leading to ordered structures when reaching the respective critical surfactant concentrations.24 Potential-tuned arrangements of surfactants have also been investigated for electrode modification, revealing the importance of the electrochemical conditions for the formation of a well-structured mesoporous phase. 25 The surfactant assembly can rearrange on the electrode surface under the influence of the applied potential, and this can be verified by measuring the differential capacity in the plating solution.26 The electroactive surface area of the soobtained mesoporous architectures is significantly increased when compared to a flat electrode. In addition, it is well-known that the active surface area of the mesoporous material also depends on the spatial arrangement of the mesopores.21-23,27 Although mesoporous materials with a largely improved active surface are readily obtained, they often suffer from a small pore size, eventually resulting in slow diffusion and access limitations, especially in the case of bulky molecules.20b In order to circumvent these drawbacks and to illustrate the benefits of a synergistic combination of macro- and mesoporous architectures, we study in this contribution the impact of macromesoporous nickel on the electrocatalytic activity for OER in alkaline medium. We demonstrate that this strategy allows promoting the electrode performance in terms of electrocatalytic current densities, which are increased by one order of magnitude compared to a flat electrode, and those electrodes also show a better stability.

Results and Discussion

Electrode elaboration

A nickel layer with hierarchical porosity $(\mathrm{Hi}-\mathrm{Ni})$ is electrodeposited on a gold electrode by a two-step approach: (i) the first step consists in electrodepositing macroporous nickel using a colloidal crystal template based on silica beads, followed by the template dissolution to create macroporous nickel (Macro-Ni) with a highly ordered porous structure; (ii) subsequently the Macro-Ni is used as a substrate for the deposition of a nickel nanosheet film in the presence of nonionic surfactant to form a mesostructured interface inside the macropores. The synthesis is illustrated in more detail in Scheme 1. Initially, well-defined layers of silica beads are generated on a gold-coated glass slide using the Langmuir-Blodgett (LB) technique (Figure S1). A highly-ordered structure of the final colloidal crystal template is obtained by controlling the surface pressure at the water-air interface during the layer-by-layer transfer. Nickel is then generated in the void space of the colloidal silica template by electrodeposition in a nickel bath. The number of deposited nickel layers can be easily monitored by using the oscillating current intensity, related to the periodical increase and decrease of the nickel deposit/electrolyte interface imposed by the colloidal crystal template. The corresponding chronoamperometric record is shown in Figure 1. 


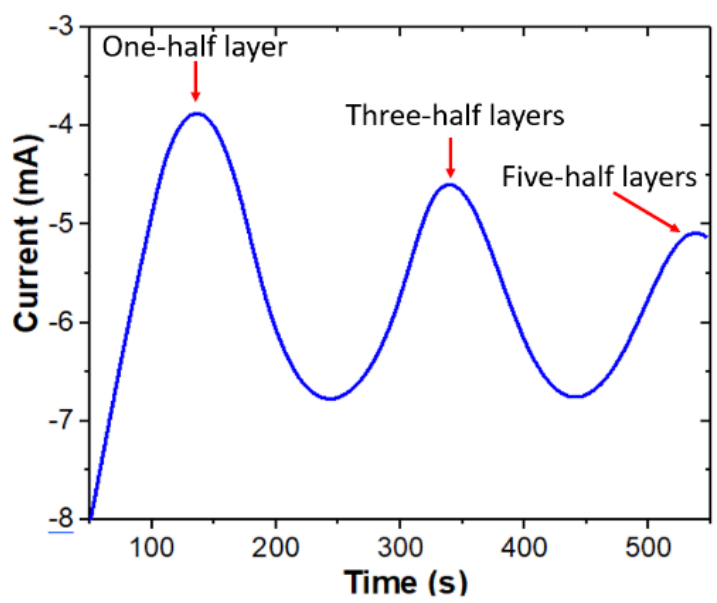

Figure 1. Chronoamperometric curve recorded during potentiostatic nickel electrodeposition through the first five half-layers of the colloidal silica-bead template (particle size of $920 \mathrm{~nm}$ diameter)

The lowest amplitude of current intensity refers to odd half-layer filling of the silica template. Usually electrodeposition is stopped at the level of odd half-layers in order to ensure completely open pores in the last layer of the final deposit. After dissolution of the silica beads a Macro-Ni electrode with a highly-ordered honeycomb-like porous structure is obtained as illustrated in Figures $2 \mathrm{a}$ and $2 \mathrm{~b}$. The dark spots in the macropores indicate the presence of connecting windows between neighboring pores.17,20a The thickness of the Macro-Ni film $(\sim 1.3 \mu \mathrm{m})$ is very uniform over the entire area as illustrated in Figure 2c.

a) Silica bead coating by LB technique

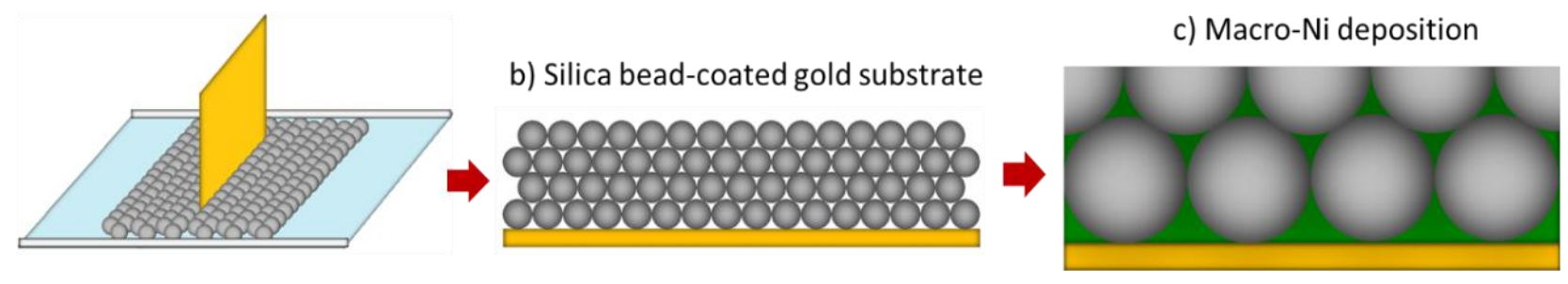

d) Silica bead dissolution by HF e) Hi-Ni deposition f) $\mathrm{Hi}-\mathrm{Ni}$ after washing

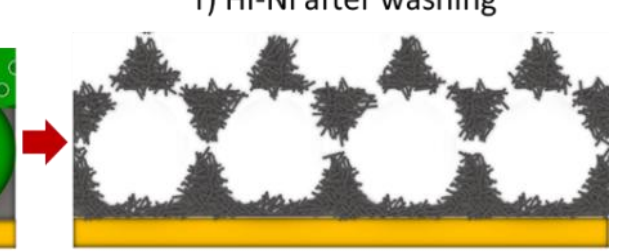

Scheme 1. Schematic illustration of the synthesis of hierarchical macro- and mesoporous nickel deposited on a gold-coated glass slide using a colloidal crystal template: a) Transfer of individual layers of silica beads onto the substrate by the LB technique; b) Final silica bead template; (c) electrodeposition of nickel; (d) silica bead dissolution leads to Macro-Ni; (e) electrodeposition of a mesoporous nickel film on the internal surface of Macro-Ni using a surfactant assembly as a template; (f) Hi-Ni after the washing step. 

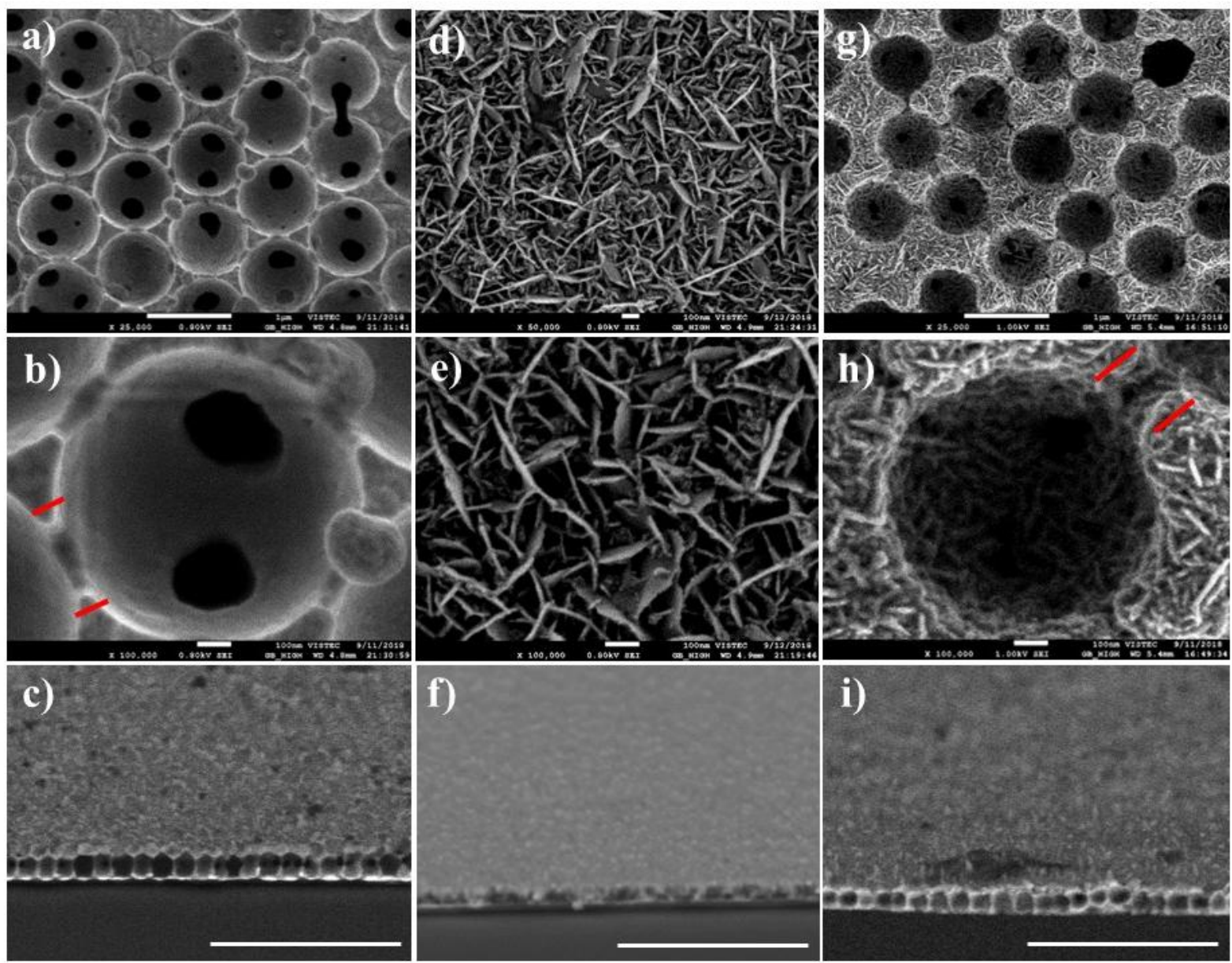

Figure 2. Scanning electron microscope (SEM) images of Macro-Ni obtained by electrodeposition in the void space of three half-layers of the colloidal silica template composed of beads with a diameter of about $920 \mathrm{~nm}$ (a: top view, scale bar $1 \mu \mathrm{m}$; b: top view, scale bar $100 \mathrm{~nm}$; c: cross section, scale bar $10 \mu \mathrm{m}$ ); Meso-Ni obtained by electrodepositing nickel with a charge of $5 \mathrm{C} \mathrm{cm}-2$ (d: low magnification, scale bar $100 \mathrm{~nm}$; e: high magnification, scale bar $100 \mathrm{~nm}$; f: cross section, scale bar 10 $\mu \mathrm{m})$; Hi-Ni obtained by electrodeposition of nickel inside the macropores ( $920 \mathrm{~nm}$ diameter) with a thickness of three half-layers (g: top view, scale bar $1 \mu \mathrm{m}$; h: top view, scale bar $100 \mathrm{~nm}$; i: cross section, scale bar $10 \mu \mathrm{m})$.

Mesoporous nickel nanosheet structures (Meso-Ni) can be formed when the nickel precursor salt is dissolved in a solution together with surfactant. A typical structure of Meso-Ni obtained by electrodeposition from a nickel bath containing a nonionic surfactant, polyoxyethylene (10) cetyl ether (Brij 56), with a deposition charge of $5 \mathrm{C} \mathrm{cm}-2$ is shown in Figures $2 \mathrm{~d}$ and 2e. Nanosheet structures are formed in the presence of surfactant during nickel deposition, even when adding only small amounts of surfactant ( $5 \mathrm{wt} . \%)$. This behavior relates to the fact that the applied potential can lead to a rearrangement of surfactants on electrode surfaces.25c Typically, the phase diagram of selfassembled surfactant molecules changes at an electrode-electrolyte interface depending on the applied potential.27a In other words, tuning of the electrode potential allows a variation of the selfassembled structure.26b In order to better understand the formation of such a concentrated 
surfactant layer at the electrode/electrolyte interface, electrodes were exposed to a Brij solution for $1 \mathrm{~min}$, while imposing various potentials $(0.1 \mathrm{~V}, 0 \mathrm{~V},-0.25 \mathrm{~V}$ and $-0.75 \mathrm{~V})$. Subsequently they were transferred into pure supporting electrolyte $(0.5 \mathrm{M} \mathrm{NaCl})$ and chronoamperometric curves were recorded at $-0.1 \mathrm{~V}$ vs Ag/AgCl (Figure S2). Currents are significantly lower for electrodes which have been modified at more negative deposition potentials, indicating that such electrodes exhibit a significant decrease in accessible active surface area compared with a bare electrode or an electrode obtained without applying any potential during the surfactant assembly. This is due to the fact that the packing density of surfactant is higher at a more negative potential. Therefore it is reasonable to assume that at quite negative potentials, a high concentration of surfactant covers the electrodeelectrolyte interface and leads to the transformation of a spherical micellar phase into a lyotropic lamellar liquid crystalline phase, resulting in a nanosheet structure during the metal deposition step.25b,26a,28 After the deposition of mesoporous $\mathrm{Ni}$, a homogeneous film thickness was observed by SEM (Figure $2 \mathrm{f}$, cross section view). The mesoporous structure has a random order due to the presence of interstitial pore space between the nanosheet layers. This allows increasing the electroactive surface area.29

To design nickel deposits with hierarchical porosity (Hi-Ni), Macro-Ni was used as the substrate for the electrodeposition in the presence of SDS as a nonionic surfactant in the nickel-plating solution. The final architecture of the hybrid meso-macropores obtained by such a two-step electrodeposition in the void space of a colloidal silica template with three half-layers of pores is illustrated in Figures $2 \mathrm{~g}$ and $2 \mathrm{~h}$. Nickel nanosheets were electrodeposited on the walls of the macropores, and in the connecting windows (indicated by red lines) between the macropores. The total thickness of the Hi$\mathrm{Ni}$ film is $\sim 1.4 \mu \mathrm{m}$ and doesn't change significantly compared to Macro-Ni because only a thin layer of nickel nanosheets is deposited as illustrated in Figure $2 \mathrm{i}$.

To confirm the crystallinity and composition of the electrodeposited nickel, thin film X-ray diffraction (XRD) patterns of all the prepared electrodes having a similar global thickness were recorded and are illustrated in Figure 3. Four main characteristic peaks of metallic nickel $(\mathrm{Ni}(0))$ appear at $2 \theta$ of 44.5 , 52.0, 76.7 and 92.7o, corresponding to the Miller indices (hkl) of crystal planes of (111), (200), (220) and (311), respectively. 30 Moreover, the presence of $\mathrm{NiO}$ and $\mathrm{NiOOH}$ was clearly observed because metallic nickel gets slightly oxidized in oxygen atmosphere as can be seen from the red and green marked peaks for $\mathrm{NiO}$ and $\mathrm{Ni}(\mathrm{OH}) 2$, respectively. An amorphous phase was also observed for all asprepared electrodes at $2 \theta$ of about 20 .

In order to characterize the electroactive surface area of the porous nickel film, cyclic voltammetry was performed in $1 \mathrm{M} \mathrm{KOH}$ in the double layer capacitive region with various scan rates $(5,10,20,50$ and $100 \mathrm{mV} \mathrm{s}-1$ ) as illustrated in Figure 4a. The specific capacitance of the different electrodes can be estimated by plotting the current density as a function of scan rate and measuring the slope (Figure 4b). To compare the electroactive surface area of several electrodes, flat nickel is used as a reference. The specific capacitance of flat nickel measured from the I-V curve is $63.3 \mu \mathrm{F} \mathrm{cm}-2$, which is comparable to the reference value of noble metals. 31 The relative surface increase is reported as roughness factor ( $\mathrm{Rf}$ ) calculated by dividing the measured capacitance by the corresponding capacitance of the flat nickel electrode (Table 1). As expected, hierarchical macro- and mesoporous nickel ( $\mathrm{Hi}-\mathrm{Ni}$ ) exhibits the highest roughness factor, followed by mesoporous nickel (Meso-Ni) and macroporous nickel (Macro-Ni) that have a similar thickness of $\sim 1.3 \mu \mathrm{m}$, respectively. This indicates that the presence of a multiscale porous structure allows enhancing the electroactive surface area in a controlled way. 


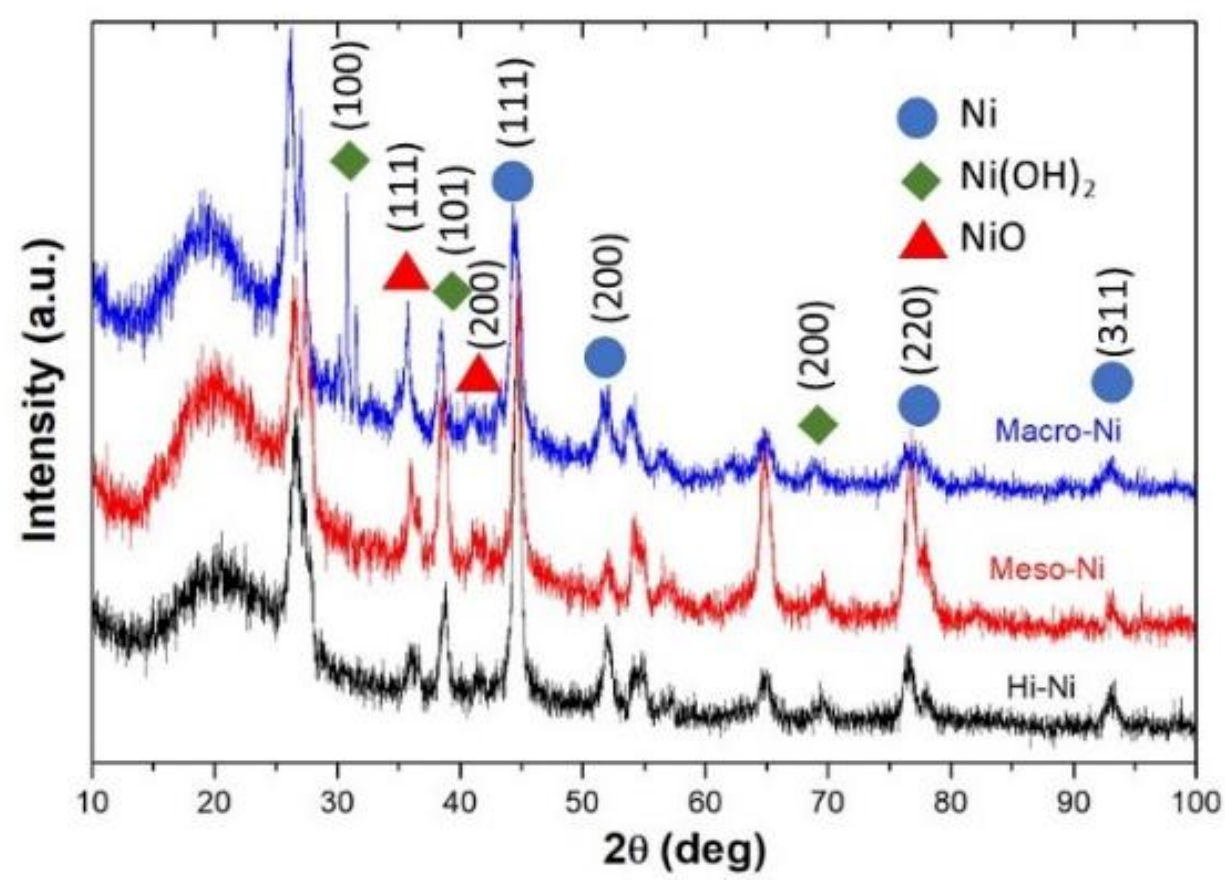

Figure 3. Thin film XRD patterns of Macro-Ni (blue), Meso-Ni (red) and Hi-Ni (black) having a comparable film thickness of $1.3,1.2$ and $1.4 \mu \mathrm{m}$, respectively.

Figure 4. (a) Cyclic volta measured in N2-saturat of the capacitive curren

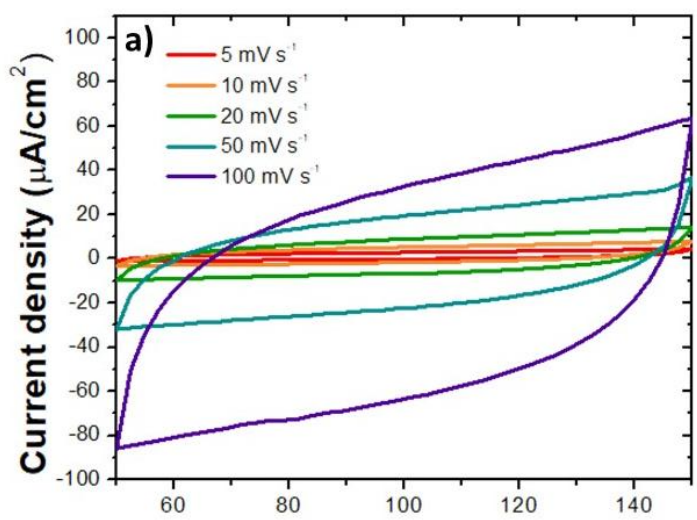

Applied potential (mV vs $\mathrm{Ag} / \mathrm{AgCl})$ electrode $(\mathrm{Hi}-\mathrm{Ni})$

f 0 to $100 \mathrm{mV}$ s-1. (b) Plot :rmine the electroactive

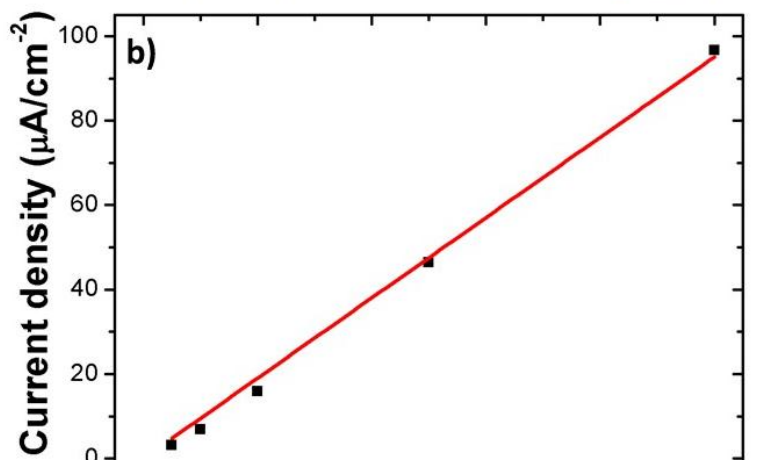


surface.

In addition, the Rf of hierarchical porous nickel increases linearly as a function of the thickness of the nickel film (Figure S3). To predict the expected roughness factors of various nickel electrodes, the theoretical relative surface enhancement between flat and porous metal electrodes can be calculated by assuming a close-packed macroporous structure.20b The theoretical enhancement factor $(f)$ for $n$ half-layers is given by Equation 1 :

$f=n \pi(4 / 3) 1 / 2$

The obtained roughness factors calculated from the double layer region of a one half-layer and a three half-layer Macro-Ni are in rather good agreement with the theoretical values (Table 1). In order to calculate the roughness factor enhancement of $\mathrm{n}$ half-layers of $\mathrm{Hi}-\mathrm{Ni}$, the one half-layer sample is used as the reference $(R f=6.9)$. Again, the experimental findings are rather close to the theoretically expected values.

Table 1. Experimental and theoretical roughness factors of various fresh and used nickel electrodes taken before and after performing OER at different applied potentials.

\begin{tabular}{|c|c|c|c|c|}
\hline \multirow{3}{*}{ Electrocatalyst } & \multicolumn{4}{|c|}{ Roughness factor } \\
\hline & \multicolumn{2}{|c|}{ Fresh electrode } & \multicolumn{2}{|c|}{ Used electrode } \\
\hline & Obtained value ${ }^{a}$ & Theoretical valueb $^{b}$ & After OER at $530 \mathrm{mVa}$ & After OER at $730 \mathrm{mVa}$ \\
\hline Flat $\mathrm{Ni}$ & 1 & - & 1.1 & 1.2 \\
\hline Meso-Ni & 8.4 & - & 10.7 & 12.7 \\
\hline One half-layer Macro-Ni & 1.9 & 1.8 & 2.4 & 3.0 \\
\hline Three half-layer Macro-Ni & 4.6 & 5.4 & 6.8 & 8.3 \\
\hline One half-layer $\mathrm{Hi}-\mathrm{Ni}$ & 6.9 & - & 8.8 & 9.3 \\
\hline Three half-layer $\mathrm{Hi}-\mathrm{Ni}$ & 15.6 & 20.7 & 21.0 & 31.5 \\
\hline Five half-layer $\mathrm{Hi}-\mathrm{Ni}$ & 33.0 & 34.5 & 34.4 & 39.9 \\
\hline
\end{tabular}

\section{Electrocatalytic oxygen evolution reaction (OER)}

To illustrate the beneficial features of hierarchical multiporous nickel nanosheets, the electrocatalytic performance for OER was studied in a solution of $\mathrm{N2}$-saturated $1 \mathrm{M} \mathrm{KOH}$, monitored by linear sweep voltammetry (LSV) in tl Figure 5 represents the by the geometric surfa

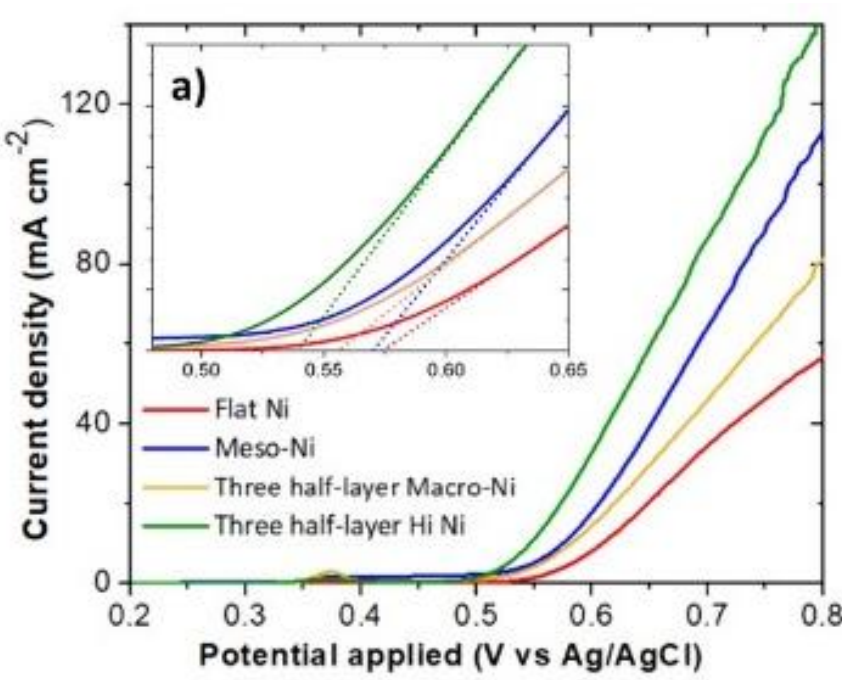
:an rate of $5 \mathrm{mV}$ s-1. ; the current divided

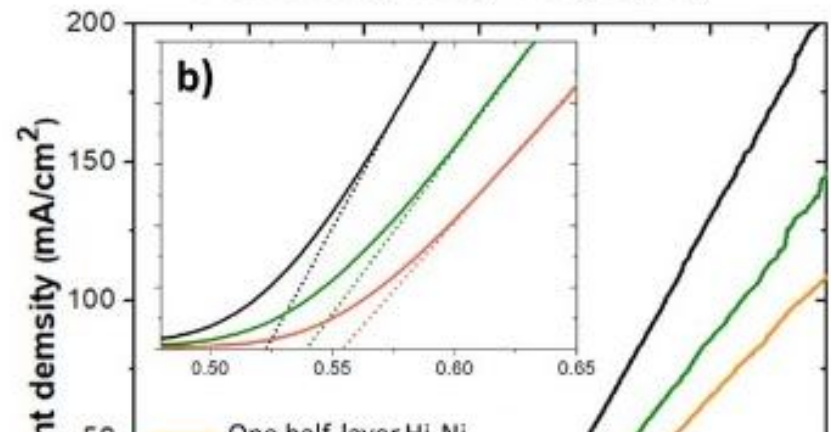


Figure 5. Linear sweep voltammograms (LSVs) for various nickel electrodes measured in N2-saturated $1 \mathrm{M} \mathrm{KOH}$ electrolyte at a scan rate of $5 \mathrm{mVs}-1$; (a) Effect of the type of nickel electrode on OER activity: flat $\mathrm{Ni}$ (red), Meso-Ni (blue), three-half layer Macro-Ni (yellow), and three-half layer Hi-Ni (green); (b) Effect of the number of electrodeposited macroporous layers on OER activity: one-half layer $\mathrm{Hi}-\mathrm{Ni}$ (orange), three-half layers $\mathrm{Hi}-\mathrm{Ni}$ (green), and five-half layers $\mathrm{Hi}-\mathrm{Ni}$ (black).

Theoretically, in alkaline solution, nickel is oxidized in the potential range from 350 to $450 \mathrm{mV}$, indicated by the small peak in Figure 5 a. The onset potential for oxygen evolution for the different nickel electrodes was measured by a linear extrapolation of the catalytic OER curves according to current recommendations.32 Compared to flat $\mathrm{Ni}$ with a similar film thickness, the OER onset potential for Meso-Ni, Macro-Ni and $\mathrm{Hi}-\mathrm{Ni}$ is slightly lower $(570,556$ and $539 \mathrm{mV} \mathrm{vs} \mathrm{Ag} / \mathrm{AgCl}$, respectively, instead of $575 \mathrm{mV}$ for flat $\mathrm{Ni}$ ). For the same class of material/composition, one would expect identical onset potential for OER. The fact that here the potentials a slighly varying might indicate that not only the morphology is changing as a function of the type of electrodeposit, but also the ratio between different oxidized nickel species ( $\mathrm{NiO}$ and $\mathrm{Ni}(\mathrm{OH}) 2$ ) and the degree of cristalinity.

Most importantly, the electrocatalytic OER performance of $\mathrm{Hi}-\mathrm{Ni}$ is significantly improved as can be seen from the higher current density compared to electrodes with a single type of porosity. This increase is due to the synergy between the high surface area of the mesoporous nanosheet structure and the improved mass transfer enabled by the macroporous structure, eventually also accelerating the evacuation of oxygen from the internal part of the porous structure.

The apparent onset potential for OER is also decreased from 559 and 539 to $523 \mathrm{mV}$ when measuring one, three and five half-layer Hi-Ni electrodes (Figure $5 b$ and Table 2). To further evaluate the performance of these electrodes we estimate the driving force necessary to achieve a current density of 10 and $100 \mathrm{~mA} \mathrm{~cm}-2$, which are values comparable to what is used in solar to fuel conversion systems.30c,33 Generally, flat Ni requires an operating potential of $630 \mathrm{mV}$, or more than $800 \mathrm{mV}$ to obtain a current density of $10 \mathrm{~mA} \mathrm{~cm}-2$ and $100 \mathrm{~mA} \mathrm{~cm}-2$, respectively. Interestingly, in the case of five half-layer $\mathrm{Hi}-\mathrm{Ni}$, a significantly lower operating potential of 524 and $660 \mathrm{mV}$ is needed for a current density of $10 \mathrm{~mA} \mathrm{~cm}-2$ and $100 \mathrm{~mA} \mathrm{~cm}-2$, respectively. These observations again confirm that the two-step electrodeposition generating hierarchical structures can improve the electrocatalytic performance for OER compared to commercial benchmarking.3c Although the values are not record numbers, 34 it shows that a controlled surface design allows gradual fine-tuning of the activity.

To gain insights into the mechanistic details of the OER for the different nickel materials, their electrocatalytic performance is examined by recording the corresponding Tafel plots $(n=b \times \log$ $(\mathrm{j} / \mathrm{j} 0)$, where $\mathrm{b}$ is the Tafel slope, $\mathrm{j}$ is current density and $\mathrm{j} 0$ is the exchange current density). 
Table 2. OER onset potentials and corresponding Tafel slopes of various nickel electrodes measured by LSV in N2-saturated $1 \mathrm{M} \mathrm{KOH}$ electrolyte at a scan rate of $5 \mathrm{mVs}-1$

\begin{tabular}{ccc}
\hline Electrode type & $\begin{array}{c}\text { Onset potential } \\
(\mathbf{m V})\end{array}$ & $\begin{array}{c}\text { Tafel slope } \\
(\mathbf{m V ~ d e c}\end{array}$
\end{tabular}

The overpotential was renormalized with respect to ERHE and calculated based on the thermodynamic value $(\eta=\mathrm{EvsAg} / \mathrm{AgCl}+0.197 \mathrm{~V}+0.059 \mathrm{pH}-1.23 \mathrm{~V})$. Under the present experimental conditions, flat $\mathrm{Ni}, \mathrm{Meso}-\mathrm{Ni}, \mathrm{Macro}-\mathrm{Ni}$ and $\mathrm{Hi}-\mathrm{Ni}$ exhibit Tafel slopes in the range from 58 to $93 \mathrm{mV}$ dec-1 (Figure 6).

Typically, the OER mechanism can be divided into three elementary steps (Equations 2-4). The first $\mathrm{OER}$ step involves the $\mathrm{OH}$ adsorption on the nickel surface $(\mathrm{Ni}-\mathrm{OH}$, Equation 2). The adsorbed $\mathrm{OH}$ species is then transformed into adsorbed $\mathrm{O}(\mathrm{Ni}-\mathrm{O}$, Equation 3 ) and finally, $\mathrm{O} 2$ gas can be produced and released from the metal surface (Equation 4).

It is well-known that the rate-determining step (RDS) of OER can be investigated by Tafel analysis if certain precautions are taken.31 As the above-mentioned Tafel slopes for the hierarchical nickel electrodes are close to $60 \mathrm{mV} \mathrm{dec}-1$, this seems to indicate that the RDS relates to the electron transfer during the $\mathrm{NiO}$ formation step.33

Figure 6. Tafel plots mei types of nickel electrod $\epsilon$ $\mathrm{Ni}$ (green). (b) Various $\mathrm{H}$
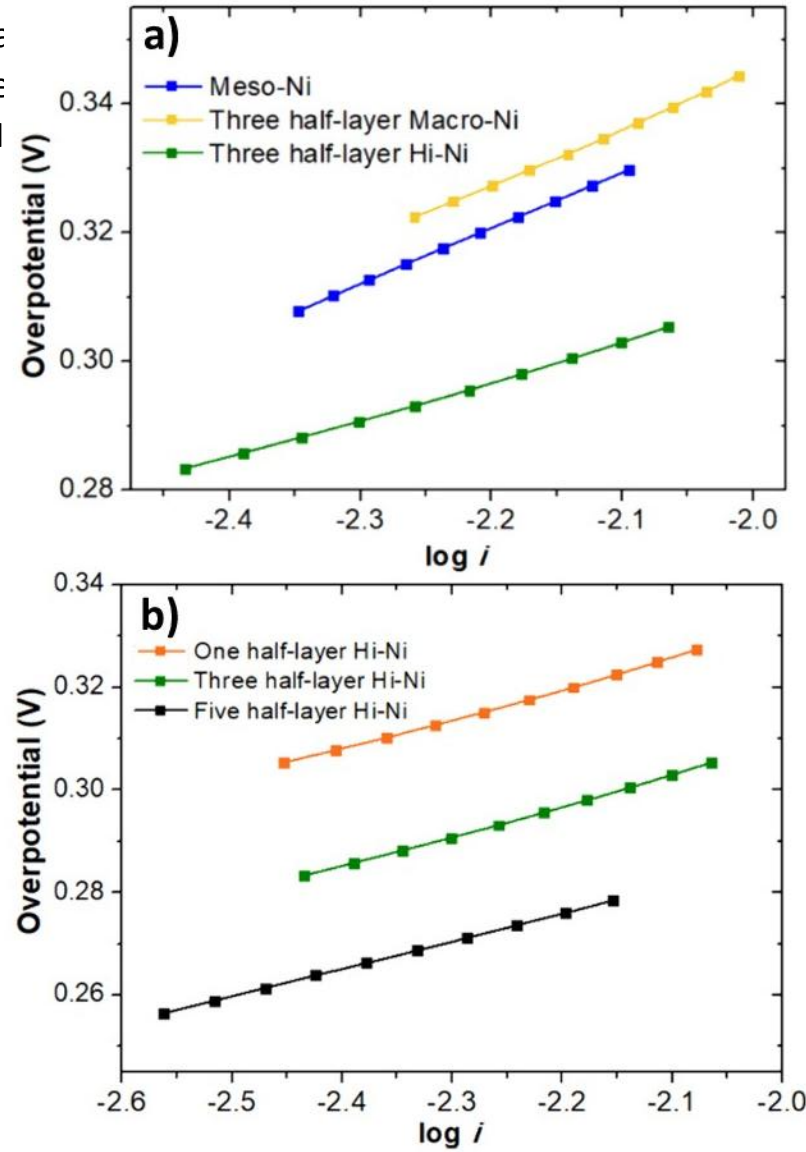

rom LSVs for (a) various and three half-layer Hisposited half-layers; one 
half-layer Hi-Ni (orange), three half-layer Hi-Ni (green), five half-layer Hi-Ni (black).

$$
\begin{aligned}
& \mathrm{Ni}+\mathrm{OH}-\rightarrow \mathrm{Ni}-\mathrm{OH}+\mathrm{e}- \\
& \mathrm{Ni}-\mathrm{OH}+\mathrm{OH}-\rightarrow \mathrm{Ni}-\mathrm{O}+\mathrm{H} 2 \mathrm{O}+\mathrm{e}- \\
& 2 \mathrm{Ni}-\mathrm{O} \rightarrow 2 \mathrm{Ni}+\mathrm{O} 2
\end{aligned}
$$

However, Tafel slopes of single pore type structures and flat Ni are above $60 \mathrm{mV}$ dec-1. This might result from a change in the rate controlling step and the material preparation method.33c,35 Theoretically, a lower Tafel slope represents a higher reactivity for OER. The Tafel slopes of various nickel electrodes, flat $\mathrm{Ni}$, Meso-Ni, three half-layer Macro-Ni and three half-layer $\mathrm{Hi}-\mathrm{Ni}$, having a similar film thickness, are 92.6, 86.6, 88.5 and $59.3 \mathrm{mV}$ dec-1, respectively. The electrodeposited Hi$\mathrm{Ni}$ benefits from the synergy between the two types of porosity and exhibits a lower Tafel slope compared to an electrode with a single type of porosity (Meso-Ni or Macro-Ni). Interestingly, increasing the number of electrodeposited pore layers allows increasing the OER performance. For example, the Tafel slope significantly decreases to $58.7 \mathrm{mV}$ dec-1 for five half-layer $\mathrm{Hi}-\mathrm{Ni}$, compared to the conventional Ni electrode $(92.6 \mathrm{mV}$ dec-1) which can show different values depending on its composition. 36 Tafel slopes can also be influenced by a low efficiency of current conduction in the solid portion of the film and in the pores.37 The related ohmic drop may strongly affect the characteristic catalytic features, but this doesn't seem to be the case for the present hierarchical structures.

In addition to the reactivity, an important aspect in catalytic systems is the stability of the electrochemical activity. This was investigated by chronoamperometry in $1 \mathrm{M} \mathrm{KOH}$ at an applied potential of 530 and $730 \mathrm{mV}$ (vs. Ag/AgCl) for $2 \mathrm{~h}$, as illustrated in Figure 7. At $530 \mathrm{mV}$ (Figure 7a), the average current density of three half-layer $\mathrm{Hi}-\mathrm{Ni}$ is $6.3 \mathrm{~mA} \mathrm{~cm}-2$, which represents the best electrochemical performance and stability, whereas the measured current densities of Meso-Ni, Macro- $\mathrm{Ni}$, and flat-Ni are significantly lower; in particular, the current density of flat $\mathrm{Ni}$ is only $1.2 \mathrm{~mA}$ $\mathrm{cm}-2$. A structure with only five half-layers of $\mathrm{Hi}-\mathrm{Ni}$ leads already to a current enhancement of around one order of magnitude compared to a flat surface. At a higher applied potential of $730 \mathrm{mV}$, flat $\mathrm{Ni}$ represents unsatisfactory stability of the signal with a rapid decrease in current density already after a few seconds as shown in Figure $7 \mathrm{~b}$. In contrast to this, $\mathrm{Hi}-\mathrm{Ni}$ exhibits a much better current stability at the same applied potential. In addition, a gradual increase of current density was obtained for Hi$\mathrm{Ni}$ as a function of the number of deposited layers (Figures $7 \mathrm{c}$ and $7 \mathrm{~d}$ ). The less pronounced decay in current for these latter electrodes might come from the fact that the formation of (nano)bubbles that often block the surface is less favorable on such structured interfaces, compared to a flat electrode where bubbles can stick more easily. 38 

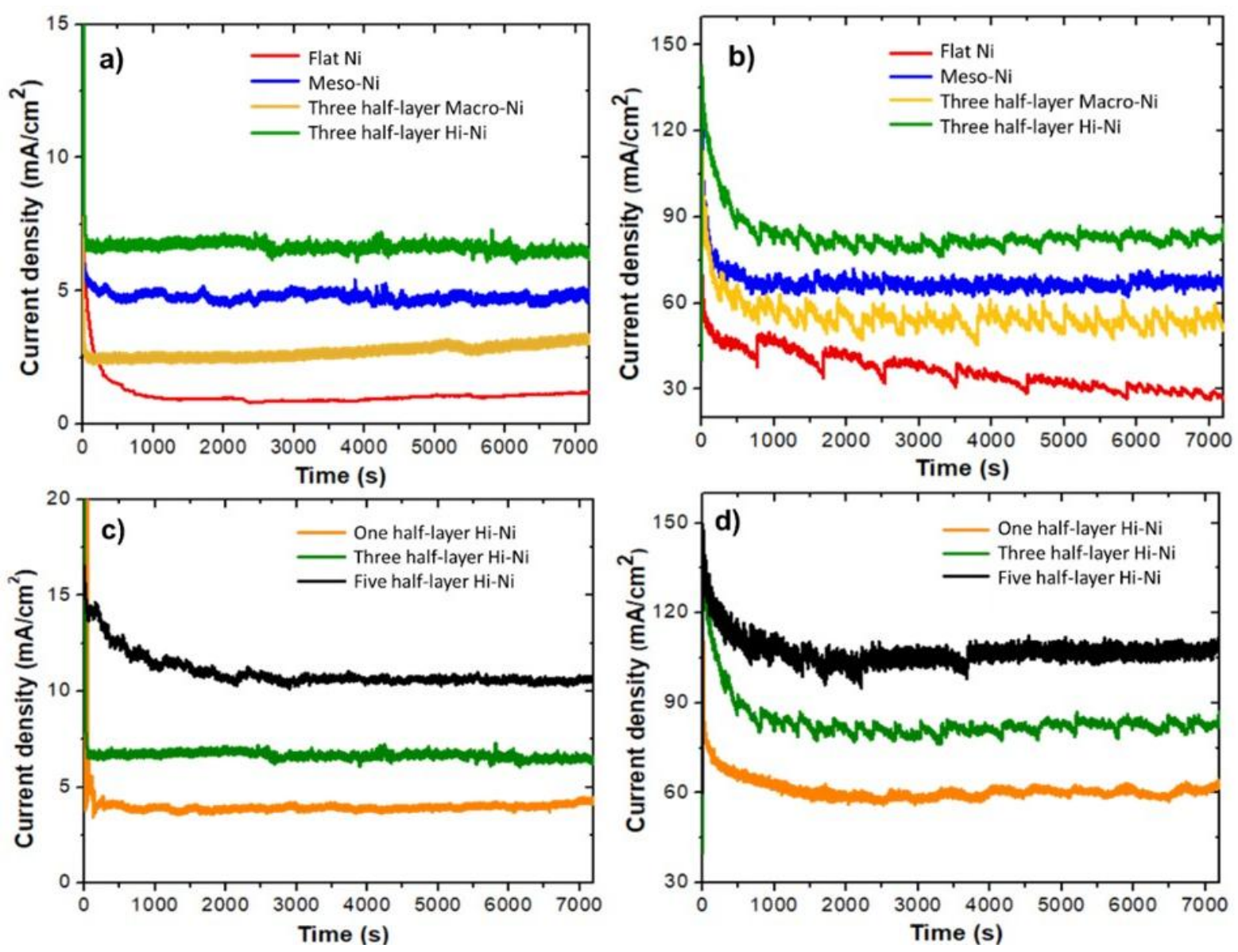

Figure 7. Chronoamperometry in $1 \mathrm{M} \mathrm{KOH}$ with various nickel electrodes at two different applied potentials; (a,b) Effect of the type of nickel on the electrocatalytic activity and stability, flat Ni (red); mesoporous $\mathrm{Ni}$ (blue); macroporous $\mathrm{Ni}$ (yellow) and hierarchical porous $\mathrm{Ni}$ (green) at an applied potential of $530 \mathrm{mV}$ and $730 \mathrm{mV}(\mathrm{vs} \mathrm{Ag} / \mathrm{AgCl})$, respectively. (c,d) Effect of the number of deposited layers of hierarchical porous $\mathrm{Ni}$ on the electrocatalytic activity and stability; one half-layer (yellow), three half-layers (green) and five half-layers (black) at a potential of $530 \mathrm{mV}$ and $730 \mathrm{mV}$ (vs $\mathrm{Ag} / \mathrm{AgCl})$, respectively.

\section{Conclusions}

In this work, we have successfully developed hierarchically structured porous nickel electrodes via a two-step electrodeposition process in the presence of silica beads and surfactant as templates to control the macro- and mesoporous structure, respectively. Highly ordered hierarchical porous 
structures with nanosheet morphologies improve the electrocatalytic active surface area compared to nickel with a single porosity. In addition, the synergetic effect of mesoporous and macroporous structures enhances the electrocatalytic current density by one order of magnitude and also improves the stability. This well-controlled design of multiporous structures constitutes a promising concept in the frame of the development of electrocatalysts for water splitting applications and might be also extended to other electrode materials.

\section{Experimental Section}

Macroporous nickel (Macro-Ni) deposition.

Silica particles of $920 \mathrm{~nm}$ diameter were synthesized following modified literature procedures,19,36,39 and then used as colloidal crystal templates transferred onto a gold-coated glass slide by using the Langmuir-Blodgett (LB) technique.15c,17,36-38 Prior to silica template deposition, the gold substrate was cleaned with isopropanol and plasma, respectively. The plating bath contains $0.7 \mathrm{M}$ nickel acetate tetrahydrate (Sigma-Aldrich, 98\%), 1.0 M nickel chloride (SigmaAldrich, 98\%), 3.0 M boric acid (Sigma-Aldrich, >99\%) in MilliQ water (18 M $\Omega$ ). Macro-Ni was electrodeposited at $-0.8 \mathrm{~V}$ vs $\mathrm{Ag} / \mathrm{AgCl}$ at room temperature, and the number of deposited layers was monitored by chronoamperometry as illustrated in Figure 1 . The macroporous structure was visualized by scanning electron microscopy after removable of the template in $10 \%$ hydrofluoric acid, which is diluted from a commercial solution (Sigma-Aldrich, 48\%), for $15 \mathrm{~min}$. In order to prevent the degradation of nickel by hydrofluoric acid, the as-prepared electrodes were rinsed with MilliQ water for $30 \mathrm{~min}$ to remove the acid solution from the pores.

Mesoporous nickel nanosheet (Meso-Ni) deposition.

A mixture containing $0.7 \mathrm{M}$ nickel acetate tetrahydrate, $1.0 \mathrm{M}$ nickel chloride, $3.0 \mathrm{M}$ boric acid and 5 wt.\% polyoxyethylene (10) cetyl ether (Brij 56) was dissolved in MilliQ water at $333 \mathrm{~K}$. Mesoporous nickel was electrodeposited by chronoamperometry at $-0.75 \mathrm{~V} v \mathrm{Ag} / \mathrm{AgCl}$ at a controlled temperature of $313 \mathrm{~K}$ in order to adjust the viscosity of the mixture. Subsequently, the modified electrode was cleaned with isopropanol and rinsed several times with MilliQ water to remove the surfactant from the pores.

Hierarchical macro- and mesoporous nickel nanosheet (Hi-Ni) deposition.

$\mathrm{Hi}-\mathrm{Ni}$ was prepared by electrodeposition of mesoporous nickel using the above-mentioned approach, but with a Macro-Ni electrode as a substrate. Typically, the electrode was immersed in the nickel bath for $15 \mathrm{~min}$ and then electrodeposition was carried out by chronoamperometry at $-0.75 \mathrm{~V}$ vs $\mathrm{Ag} / \mathrm{AgCl}$ and $313 \mathrm{~K}$. After electrodeposition, the prepared electrode was rinsed several times to remove the surfactant from the hierarchical pore structure.

Electrochemical characterization.

All electrochemical characterizations were performed with a $\mu$ AUTOLAB type III in an electrochemical cell with a three-electrode configuration. The prepared nickel electrodes (Macro-Ni, Meso-Ni, $\mathrm{Hi}-\mathrm{Ni}$ ) were used as a working electrode, a platinum mesh and $\mathrm{Ag} / \mathrm{AgCl}$ (sat. $\mathrm{KCl}$ ) 40 were used as a counter and reference electrode, respectively. The active surface area of the electrodes was measured by cyclic voltammetry (CV) in the capacitive region between 0 and $100 \mathrm{mV}$ vs $\mathrm{Ag} / \mathrm{AgCl}$ in $1 \mathrm{M} \mathrm{N2}$ saturated $\mathrm{KOH}$ at various scan rates. The activity with respect to the oxygen evolution reaction (OER) was measured by linear sweep voltammetry (LSV) in basic solution with nitrogen bubbling from $0.2 \mathrm{~V}$ to $0.8 \mathrm{~V}$ with a scan rate of $5 \mathrm{mV} . \mathrm{s}-1$ and potentials were converted to $\mathrm{RHE}(\mathrm{ERHE}=\mathrm{EAg} / \mathrm{AgCl}+0.197$ 
$\mathrm{V}+0.059 \mathrm{pH}$ ). The stability of the nickel electrodes was studied at two different potentials: (i) 530 $\mathrm{mV}$ and (ii) $730 \mathrm{mV}$ for slow and fast OER rate after $2 \mathrm{hrs}$ reaction time.

Surfactant assembly study.

Chronoamperometry was used to investigate the effect of self-assembly of surfactant on the electrode surface during electrodeposition. Several gold-coated glass slides were exposed to a solution of $5 \%$ wt Brij 56 in $3.0 \mathrm{M}$ boric acid while applying different potentials ranging from $-0.75 \mathrm{~V}$ to $0.1 \mathrm{~V}$ for $1 \mathrm{~min}$. The surfactant modified electrodes were then rinsed with miliQ water and directly transferred to a $0.5 \mathrm{M} \mathrm{NaCl}$ solution in order to measure the current decay at an applied potential of $0.1 \mathrm{~V} \mathrm{vs} \mathrm{Ag} / \mathrm{AgCl}$ for $1 \mathrm{~min}$.

Scanning electron microscope (SEM).

To study the surface morphology and the number of pore layers, scanning electron microscopy was performed on a Hitachi TM-1000 tabletop microscope and a JEOL JSM-7610F.

\section{Acknowledgements}

We would like to thank the technical assistance of the Vidyasirimedhi Institute of Science and Technology (VISTEC) FRC for SEM characterization. This work was supported by the bilateral PICS program of CNRS. A.K. thanks the Institut Universitaire de France for financial support. Chu. W. thanks the Thailand Research Fund (TRF) (MRG6180099), the Office of Higher Education Commission (OHEC) and TTSF research project supported by Thailand Toray Science Foundation. In addition, this work has been partially supported by the National Nanotechnology Center (NANOTEC), NSTDA, Ministry of Science and Technology, Thailand, through its program of Research Network NANOTEC (RNN). S.A. is grateful to the French Embassy in Thailand and VISTEC for a Ph.D. cotutelle scholarship. The project has also been partially funded by the European Research Council (ERC) under the European Union's Horizon 2020 research and innovation program (grant agreement no 741251, ERC Advanced grant ELECTRA)

Keywords: Porous nickel • Oxygen evolution reaction (OER) • Mesoporous material • Macroporous material • Electrocatalysis

(1) (a) Y. Liang, Y. Li, H. Wang, H. Dai, J. Am. Chem. Soc. 2013, 135, 2013-2036; (b) J. Liu, Y. Liu, N. Liu, Y. Han, X. Zhang, H. Huang, Y. Lifshitz, S. T. Lee, J. Zhong, Z. Kank, Science 2015, 347, 970-974; (c) X. Zhang, X. Zhang, H. Xu, Z. Wu, H. Wang, Y. Liang, Adv. Funct. Mater. 2017, 27, 1606635; (d) J. H. Kim, J. W. Jang, Y. H. Jo, F. F. Abdi, Y. H. Lee, R. Krol, J. S. Lee, Nat. Comm. 2016,7, 13380; (e) C. Ding, J. Shi, Z. Wang, C. Li, ACS Catal. 2017, 7, 675-688; (f) Z, Wang, C. Li, K. Domen, Chem. Soc. Rev. 2019, 48, 2109-2125.

[2] C. C. L. McCrory, S. Jung, I. M. Ferrer, S. M. Chatman, J. C. Peters, T. F. Jaramillo, J. Am. Chem. Soc. 2015, 137, 4347-4357.

[3] (a) T. T. H. Hoang, A. A. Gewirth, ACS Catal. 2016, 6, 1159-1164; (b) X. Lu, C. Zhao, Nat. Commun. 2015, 6, 6616; (c) C. C. L.McCrory, S. Jung, J. C. Peters, T. F. Jaramillo, J. Am. Chem. Soc. 2013, 135, 16977-16987.

[4] (a) A. R. Zeradjanin, A. A. Topalov, Q. V. Overmeere, S. Cherevko, X. Chen, E. Ventosa, W. Schuhmann, K J. J. Mayrhofer, RSC Adv. 2014, 4, 9579-9587; (b) Y. Lee, J. Suntivich, K. J. May, E. E. Perry, Y. S. Horn, J. Phys, Chem. Lett. 2012, 3, 399-404. 
[5] (a) R. Kötz, S. Stucki, D. Scherson, D. M. Kolb, J. Electroanal. Chem. Interf. Electrochem. 1984, 172, 211-219; (b) I.Roger, M. A. Shipman, M. D. Symes, Nat. Rev. Chem. 2017, 1, 0003; (c) S. Cherevko, S. Geiger, O. Kasian, N. Kulyk, J. P. Grote, A. Savan, B. R. Shrestha, S. Merzlikin, B. Breitbach, A. Ludwig, K. J. J. Mayrhofer, Catal. Today 2016, 262, 170-180.

[6] (a) C. Tang, N. Cheng, Z. Pu, W. Xing, X. Sun, Angew. Chem. Int. Ed. Engl. 2015, 54, 9351-9355; (b) X. Wang, W. Li, D. Xiong, L. Liu, J. Mater. Chem. A 2016, 4, 5639-5646.

[7] (a) L. K. Wu, W. Y. Wu, J. Xia, H. Z. Cao, G. Y. Hou, Y. P. Tang, G. Q. Zheng, J. Mater. Chem. A 2017, 5, 10669-10677; (b) L. Chen, H. Guo, T. Fujita, A. Hirata, W. Zhang, A. Inoue, M. Chen, Adv. Funct. Mater. 2011, 21, 4364-4370.

[8] M. Shalom, D. Ressnig, X. Yang, G. Clavel, T. P. Fellinger, M. Antonietti, J. Mater. Chem. A 2015, 3, 8171-8177.

[9] (a) H. Sun, X. Xu, Z. Yan, X. Chen, F. Cheng, P. S. Weiss, J. Chen, Chem. Mater. 2017, 29, 85398547; (b) J. Chang, K. Li, Z. Wu, J. Ge, C. Liu, W. Xing, ACS Appl. Mater. Interfaces 2018, 10, 26303 26311.

[10] (a) A. Sivanantham, S. Shanmugam, Appl. Catal. B 2017, 203, 485-493; (b) A. T. Swesi, J. Masud, M. Nath, Energy Environ. Sci. 2016, 9, 1771-1782.

[11] (a) T. Tian, H. Gao, X. Zhou, L. Zheng, J. Wu, K. Li, Y. Ding, ACS Energy Lett. 2018, 3, 2150-2158;

(b) E. A. Duran, Y. Meas, J. J. P. Bueno, J. C. Ballesteros, G. Trejo, Electrochim. Acta 2018, 268, 49-58.

[12] (a) C. Luan, G. Liu, Y. Liu, L. Yu, Y. Wang, Y. Xiao, H. Qiao, X. Dai, X. Zhang, ACS Nano 2018, 12, 3875-3885; (b) X. Wang, H. Luo, H. Yang, P. J. Sebastian, S. A. Gamboa, Int. J. Hydrogen Energ. 2004, 29, 967-972.

[13] (a) Y. Jiao, Y. Zheng, M. Jaroniec, S. Z. Qiao, Chem. Soc. Rev. 2015, 44, 2060-2086; (b) L. L. Feng, G. Yu, Y. Wu, G. D. Li, H. Li, Y. Sun, T. Asefa, W. Chen, X. Zou, J. Am. Chem. Soc. 2015, 137, 1402314026; (c) Z. Chen, L. Cai, X. Yang, C. Kronawitter, L. Guo, S. Shen, B. E. Koel, ACS Catal. 2018, 8, 12381247.

[14] V. Vij, S. Sultan, A. M. Harzandi, A. Meena, J. N. Tiwari, W. G. Lee, T. Yoon, K. S. Kim, ACS Catal. $2017,7,7196-7225$.

[14] (a) K. M. Hercule, Q. Wei, A. M. Khan, Y. Zhao, X. Tian, L. Mai, Nano Lett. 2013, 13, 5685-5691; (b) G. Du, Q. Bian, J. Zhang, X. Yang, RSC Adv. 2017, 7, 46329-46335; (c) M. Heim, L. Rousseau, S. Reculusa, V. Urbanova, C. Mazzocco, S. Joucla, L. Bouffier, K. Vytras, P. Bartlett, A. Kuhn, B. Yvert, J. Neurophysiol. 2012, 108, 1793-1803.

[16] (a) N. B. J. Hetherington, A. N. Kulak, Y. Y. Kim, E. H. Noel, D. Snoswell, M. Butler, F. C. Meldrum, Adv. Funct. Mater. 2010, 21, 948-954; (b) W. S. Kim, L. Jia, E. L. Thomas, Adv. Mater. 2009, 21, 19211926; (c) D. V. Gough, A. T. Juhi, P. V. Braun, Mater. Today 2009, 12, 28-35.

[17] M. Heim, C. Wattanakit, S. Reculusa, C. Warakulwit, J. Limtrakul, S. Ravaine, A. Kuhn, Electroanal. $2013,25,888-894$.

[18] (a) R. Szamocki, S. Reculasa, S. Ravaine, P. N. Bartlett, A. Kuhn, R. Hempelmann, Angew. Chem. Int. Ed. 2006, 45, 1317-1321; (b) X. Li, G. Zhang, X. Bai, X. Sun, X. Wang, E. Wang, H. Dai, Nat. Nanotechnol. 2008. 3, 538-542; (c) D. M. Guldi, I. Zibermann, G. A. Anderson, K. Kordatos, M. Prato, R. Tafuro, L. Valli, J. Mater. Chem. 2004, 14, 303-309. 
[19] M. Heim, S. Reculusa, S. Ravaine, A. Kuhn, Adv. Funct. Mater. 2012, 22, 538-545.

[20] (a) V. Urbanová, K. Vytřas, A. Kuhn, Electrochem. Comm. 2010, 12, 114-117; (b) R. Szamocki, A. Velichko, C. Holzapfel, F. Mücklich, S. Ravaine, P. Garrigue, N. Sojic, R. Hempelmann, A. Kuhn, Anal. Chem. 2007, 79, 533-539.

[21] B. Tieke, Adv. Mater. 1991, 3, 532-541.

[22] J. Lenz, V. Trieu, A. Kuhn, ECS Trans. 2011, 33, 19-25.

[23] (a) M. S. Kim, L. Ma, S. Choudhury, S. S. Moganty, S. Wei, L. A. Archer, J. Mater. Chem. A 2016, 4, 14709-14719.

[24] (a) Y. Yamauchi, K. Kuroda, Chem. Asian. J. 2008, 3, 664-676; (b) G. S. Attard, P. N. Bartlett, N. R. B. Coleman, J. M. Elliott, J. R. Owen, J. H. Wang, Science 1997, 278, 838-840.

[25] (a) J. F. Rusling, H. Zhang, Langmuir 1991, 7, 1791-1796; (b) S.Sotiropoulos, P. Nikitas, N. Papadopoulos, J. Electroanal. Chem. 1993, 356, 201-223; (c) A. Walcarius, E. Sibottier, M. Etienne, J. Ghanbaja. Nat. Mater. 2007, 6, 602-608; (d) K. S. Choi, H. C. Lichtenegger, G. D. Stucky. J. Am. Chem. Soc. 2002, 124, 12402-12403.

[26] (a) I. Burgess, C. A. Jeffrey, Z. Cai, C. G. Szymanski, Z. Galus, J. Lipkowski, Langmuir 1999, 15, 2607-2616; (b) N. Kobayashi, H. Saitoh, R. Kawamura, H. Y. Yoshikawa, S. Nakabayashi, J. Electroanal. Chem. 2017, 799, 444-450.

[27] (a) S. Pavasupree, S. Ngamsinlapasathian, Y. Suzuki, S. Yoshikawa, Materials Letters 2007, 61, 2973-2977; (b) U. Suryavanshi, V. V. Balasubramanian, K. S. Lakhi, G. P. Mane, K. Ariga, J. H. Choy, D. H. Park, A. M. A. Enizi, A. Vinu, Phys. Chem. Chem. Phys. 2014, 16, 23554-23557; (c) X. Huang, N. P. Young, H. E. Townley, Nanomater. Nanotechnol. 2014, 4, 1-15.

[28] I. Burgess, V. Zamlynny, G. Szymanski,; J. Lipkowski, J. Majewski, G. Smith, S. Satija, R. Ivkov, Langmuir 2001, 17, 3355-3367.

[29] (a) H. W. Liang, W. Wei, Z. S. Wu, X. Feng, K. Müllen, J. Am. Chem. Soc. 2013, 135, 16002-16005;

(b) Q. Qu, J. H. Zhang, J. Wang, Q. Y. Li, C. W. Xu, X. Lu, Scienctific Report 2017, 7, 41542.

[30] (a) A. K. Sharma, S. Desnavi, C. Dixit, U. Varshney, Extraction of nickel nanoparticles from electroplating waste and their application in production of bio-diesel from biowaste. Conference:

ICCCE 2014, Singapore; (b) C.; Jayaseelan, A. A. Rahuman, R. Ramkumar, P. Perumal, G. Rajakumar, A. V. Kirthi, T. Santhoshkumar, S. Marimuthu, Ecotox. Environ. Safe.2014, 107, 220-228; (c) J. Tientong, S. Garcia, C. R. Thurber, T. D. Golden, J. Nanotechnol. 2014, 2014, 193162.

[31] M. Lukaszewski, M. Soszko, A. Czerwinski, Int. J. Electrochem. Sci. 2016, 11, 4442-4469.

[32] D. Voiry, M. Chhowalla, Y. Gogotsi, N. A. Kotov, Y. Li, R. M. Penner,; R. E. Schaak, P. S. Weiss, ACS Nano 2018, 12, 9635-9638.

[33] (a) D. R. Kauffman, D. Alfonso, D. N. Tafen, J. Lekse, C. Wang, X. Deng, J. Lee, H. Jang, J. S. Lee, S. Kumar, C. Matranga, ACS Catal. 2016, 6, 1225-1234. (b) K. Juodkazis, J. Juodkazyté, R. Vilkauskaité, V. Jasulaitiené, J. Solid State Electrochem. 2008, 12, 1469-1479; (c) E. B. Castro, C. A. Gervasi, Int. J. Hydrogen Energy. 2000, 25, 1163-1170; (d) R. F. Scarr, J. Electrochem. Soc. 1969, 116, 1526-1532; (e) R. L. Doyle, I. J. Godwin, M. P. Brandon, M. E. G. Lyons, Phys. Chem. Chem. Phys. 2013, 15, 1373713783; (f) V. I. Birss, A. Damjanovic, P. G. Hudson, J. Electrochem. Soc. 1986, 133, 1621-1625; (g) Y. H. Fang, Z. P. Liu, J. Am. Chem. Soc. 2010, 132, 18214-18222. 
[34] L. A. Stern, X. Hu, Faraday Discuss. 2014, 176, 363-379.

[35] (a) R. N. Singh, J. F. Koenig, G. Poillerat, P. Chartier, J. Electrochem. Soc. 1990, 137, 1408-1413. (b) I. Nikolov, R. Darkaoui, E. Zhecheva, R. Stoyanova, N. Dimitrov, T. Vitanov, J. Electrochem. Chem.1997, 429, 157-168.

[36] S. Reculusa, M. Heim, F. Gao, N. Mano, S. Ravaine, A. Kuhn, Adv. Funct. Mat. 2011, 21, 691-698.

[37] C. P. Andrieux, C. Costentin, C. D. Giovanni, J. M. Savéant, C. Tard, J. Phys. Chem. C, 2016, 120, 21263-21271

[38] H. A. E. Sayed, A. Weiß, L. F. Olbrich, G. P. Putro, H. A. Gasteiger, J. Electrochem, Soc. 2019, 100, 458-464.

[39] S. Reculusa, S. Ravaine, Chem. Mater, 2003, 15, 598-605.

[40] (a) W. Zhou, X. J. Wu, X. Cao, X. Huang, C. Tan, J. Tian, H. Liu, J. Wang, H. Zhang, Energy Environ. Sci. 2013, 6, 2921-2924; (b) J. Ahmed, T. Ahamad, S. M. AlShehri, ChemElectroChem, 2017, 4, $1222-$ 1226; (c) Q. Niu, J. Guo, B. Chen, J. Nie, X. Guo, G. Ma, Carbon, 2017, 114, 250-260. 